\title{
What plus-size means for plus-size women: A mixed-methods approach
}

\author{
Deborah A. Christel, President and CEO of Kade \& Vos* \\ Susan C. Williams Née Dunn, Washington State University, Department of Apparel Merchandising, \\ Design and Textile \\ *Corresponding author: deborah.christel@kadevos.com
}

\begin{abstract}
Western fashion is constantly evolving and in order to obtain notoriety, brands need to positively connect with consumers. Individuals who wear plus-sizes are acutely aware of their reduced clothing choices and rely on language cues to find clothing. Unfortunately, the categorisation of plus-size consumers is fraught with discord and frustration. Fashion communication should consider consumer needs and preferences. However, the language used to classify plus-size consumers has yet to be examined. Plus-size women were recruited online to rate twelve terms associated with plus-size women's clothing. The survey collected a total of 324 responses of age, height, weight and ratings of terms used to classify plus-size apparel, such as Women's, Curvy. Data were analysed using descriptive statistics and analysis of variance to compare differences considering age and body mass. This study revealed $96 \%$ of the sample ranked the classification Women's higher than Plus-Size. The study offers insights into how plus-size consumers view sizing communications. It also offers a useful ranking of terms that fashion companies can adopt to ensure they are communicating in language that the intended consumer prefers. This study contributes to research on social identity of clothing size, plus-size consumer experiences, and further validates the multidimensional challenges faced by plus-size consumers.
\end{abstract}

\section{Keywords}

plus-size, communication retail strategy, merchandising, narrative, mixed-methods, consumers, apparel, fashion, marketing

\section{Introduction}

The plus-size consumer has gained attention from retailers over the past decade as apparel companies continue to publicly contemplate the inclusion or exclusion of plus-size clothing. Current estimates suggest that over $67 \%$ of American women wear plus-sizes (Garcia, 2015) and as limited retail establishments offer plus-sizes, this issue is now critical and hotly debated in fashion media (Czerniawski, 2015; Kim, Jolly \& Kim, 2007; Norman, 2017; Scaraboto \& Fischer, 2016). Plus-sizes are loosely classified as women's numerical sizing 14 and above (Bogenrief, 2012). "Size 14 typically caps the size charts of most American-distributed stores and brands" (Christel, 2016, p. 1; see also Alexander, Pisut, \& Ivanescu, 2012; Peters, 2015). Meanwhile, "the average American woman, including
White, Black and Mexican-American races and ethnicities, now wears between a Misses size 16-18" (Christel \& Dunn, 2016, p. 4). Despite the millions of average size customers who are eager to buy, plus-size fashion greatly suffers from marketing and merchandising neglect (Anderson \& Simester, 2008).

There is little consensus what qualifies plus-size clothing and as fashion rapidly changes, the way brands communicate with consumers must adapt. Lee and Steen (2015) state, "Women's (plus) is listed as $1 \mathrm{X}-4 \mathrm{X}$ and $14 \mathrm{~W}$ to $28 \mathrm{~W}$ " (p. 279). Bubonia (2012) states that “[w]omen's designates full figure adult females using even numbers followed by W's. Sizes in this range typically include 14W-24W" (p. 165). Furthermore, Brown and Rice (2014) define the plus-size category as: 
Women's sizes fit the adult woman of average height who has a full, mature figure. Women's sizes feature less waist definition and longer sleeves than Misses sizes. Plus-sizes, large size, or Women's departments and specialty stores are increasingly likely to designate Women's sizes for what were formerly Misses size designations, for example, even numbered sizes 16 to 20 or 14 to 24 . Thus, it is often unclear whether a garment was designed for a large Misses figure type or a true Women's figure type - the two differ. (p. 207)

An analysis of the top grossing 100 U.S. online retailers found that plus-sizes range in size designations from $12-38 \mathrm{~W}$ and $0 \mathrm{X}-6 \mathrm{X}$ with variations up to 11.5 " in measurements for the same size designation (Dunn, 2016). The vast definitions and differing proportions in plus-sizes, while well-meaning, further muddle the functional purpose of the classification (Norman, 2017). While the term plus-size is viewed as marginalising, it also serves a functional purpose and thus has dual meaning; plus-size is both a social construct that marginalises women and plussize is a merchandising category that helps women locate clothing sizes (Peters, 2015, see also Christel, 2018). There is anecdotal evidence written about plus-size categorisation, yet no academic or peer reviewed studies have been asserted to determine the usage, opinions or preferences of the plus-size consumer. Furthermore, the designation of plus-size was constructed without accord or consideration of the growing market.

Popular press suggests that plus-size women are marginalised and are frequently treated with less respect than thinner women (Refinery29, 2016). To combat the discrimination, several social movements have emerged. For example, \#plusisequal, Dove's Real Beauty campaign, the fat acceptance movement, and the body-positive movement. The body-positive movement encourages people to adopt more forgiving and affirming attitudes towards their bodies, with the goal of improving health and well-being instead of a goal body weight. In conjunction with that movement, popular culture has disputed the term plus-size and some seek to eliminate its use entirely (Garcia, 2015). The term is viewed as problematic because, many women feel the category is marginalising and suggests they are a small group outside the mainstream whose fashion needs are secondary. On the other hand, some women feel the plus-size classification helps them locate their clothing sizes. A popular culture article from 2015 surveyed plus-size women's mixed feelings about the term plus-size. A woman stated,

\begin{abstract}
"there is an underlying stigma about someone who wears 'plus-size' clothing is also linked to the negative connotations of terms such as 'fat,' 'obese' or 'unhealthy,'” while another stated, "I don't mind it; it makes finding my clothes easier. But it's not the reality of American (especially women's) sizes.” (Avilia, 2015)
\end{abstract}

Newer designers, such as Melissa McCarthy, agree with the sentiment and eliminated the use of any plus-size narrative in their clothing collections (Wang, 2015). Department stores have signage indicating sections of merchandise typically classified by gender and age. For example, the Juniors department refers to females in their teen years and is typically styled for youthful appeal. Other designations include the children's section, misses, women's, and men's departments. However, the plus-size classification groups a demographic by size and does not directly indicate consumer gender or age. This merchandising structure is the first in which a mass market clothing section provides apparel by size without considering gender, style, demographic or psychographic data. Plus-size apparel must consider more than size, because target market spans age, lifestyle, values, interests, attitudes, marital or relationship status, socioeconomic status, political perspectives, occupation, sex, gender, sexuality, social participation, and geography, amongst others (Ryan, 1966). These diverse factors require different styles at a variety of price points. Many retailers consider style preferences that correspond to certain age groups, such as Juniors, but style preference by age group has little consideration for plus-size indi- 
viduals. While smaller adult women may shop in Juniors, which has its own assumptions of styles, larger women have no alternative female section to choose from. Further complicating shopping behaviour, and highlighting the social group identity and privilege accompanied with being thin, some plus-size women resort to shopping in the men's sections to find items that fit their bodies (Christel, O’Donnell, \& Bradley, 2016).

Collectively, the purpose of this study is to identify terms that plus-size women find desirable for communicating their clothing classification. It is our hope to provide, through empirical research and theoretical analysis, a voice for larger consumers and clear information to retailers about the plus-size market, how language in fashion communication is perceived amongst plus-size consumers, and whether retailers should modify their approach.

\section{Literature review}

Social identity theory posits that a person's sense of who they are is based on their group membership(s). In this regard, Tajfel and Turner (1979) proposed that the groups which people belonged to (e.g., social class, family etc.) were an important source of pride and self-esteem. "Groups give us a sense of social identity: a sense of belonging to the social world" (McLeod, 2008). Based on cognitive groupings, humans naturally group objects, events and people. This is further recognised as in-group (us) and out-group (them). Therefore, our culture divides people into them and us through a process of social categorisation (McLeod, 2008). Through this natural categorisation, the difference between groups and similarities of each group are exaggerated (see also, Tajfel \& Turner, 1979.

Social identity theory speculates that humans are motivated to enhance and protect the self, in order to increase self-image and enhance the status of the group to which they belong (Tajfel \& Turner, 1979). It has also been found that in-groups can increase self-image by discriminating and holding prejudiced views against the outgroup (Tajfel \& Turner, 1979). The central hypothesis of social identity theory is that in-group members look for negative aspects of people in the out-group, as a way to increase the in-group self-image (McLeod, 2008).

Previous research indicates that individuals have social identities with age (Garstka, Hummert \& Branscombe, 2005; Twigg, 2014), abilities and disabilities (Bogart, 2015; Buse \& Twigg, 2015), and sex and gender (Pauletti, Cooper, Aults, Hodges, \& Perry, 2016). Each of the aforementioned concepts are physical traits as well as socially constructed phenomena. In the same respect, body weight and size is both a physical trait and a socially constructed clothing category. One study found that body weight and size have the properties of a social identity and that overweight and "obese" women have a stronger identity with weight than normal weight women. In this regard, Asbury (2011) found there are cognitive, affective and behavioural components of weight identity which may help explain why women often say, I am a size __ instead of I wear a size

Considering weight and size as a social identity; thin consumers would be categorised as the in-group and plus-size consumers as the out-group. The groupings are divided by the many negative character traits associated with "obese" or plus-size individuals (Eisenberg, Street \& Persky, 2016). People with a larger body are associated with negative characteristics such as lazy, weak-willed, unintelligent, and non-compliant with diet and exercise (Diedrichs \& Puhl, 2016; Durso, Latner, \& Ciao, 2016). From social identity theory, the prejudice views of larger people serve to enhance the self-image of thin individuals which maintain the group structures. As clothing is inexorably linked to the body and aids in communicating roles and identity (Allik \& Realo, 2004; Celik, 2016; Nagar \& Gandotra, 2016; Tiggman \& Lacey, 2009), it is critical to examine our communications with plus-size consumers, or in this scenario, the out-group of the fashion industry. 
McMichael argues, "While fatter people in contemporary society are often subjected to weight-based oppression, thin people are conversely advantaged by this system of oppression. 'Thin privilege' refers to the unearned advantages conferred to thinner people. It is a key pathway through which fat oppression is maintained. Often invisible, thin privilege fundamentally shapes our lives" (McMichael, 2013, as cited in Bacon, O’Reilly \& Aphramor, 2016, p. 42). Having a thin body means that you can turn on the television and see people with your figure, fit into seats and desks comfortably, receive better quality healthcare, are more likely to get a job and promotions, have little educational barriers, and are treated with more respect at restaurants (Rothblum \& Solovay, 2009). Thin privilege also includes being able to go to any clothing store, as opposed to specialty stores, and find clothing in your size (Bacon, O’Reilly, \& Aphramor, 2016).

There are rarely words used to classify non-plus size clothing because, anything other than plus-size is considered the norm, standard, regular or in-group. The importance of being thin is perpetuated by fewer plus-size clothing options (Christel, 2014), and this practice maintains the power of who can and cannot participate in certain fashions. Words used to define consumer groups remain a critical tenet of fashion communications that studies communication in design through visual branding, trends, culture, styling and imagery, digital illustration, social media, brand development and brand management. This exploratory study examined language used in the fashion industry for plus-size consumers through an online survey. The objective was to determine the terms that plus-size women find desirable or undesirable for the fashion industry to use in communicating their clothing classification and to further analyse the findings within social identity theory and fashion communication. Based on the literature review, the following research questions are posed:

, RQ1. What are the most and least preferred terms for plus-size women?
, RQ2. What are the preferred terms categorised by BMI? Does body mass affect plus-size women's preferred terms for apparel signage?

, RQ3. What are the preferred terms categorised by age group? Does age affect plus-size women's preferred terms for apparel signage?

\section{Methods}

During the spring of 2016 participants were recruited via purposive sampling with an advertisement posted on a public news webpage of the researchers' institution located in the North West of the United States. The advertisement requested women aged 18 and over, who identified as plus-size and/or wear women's size 14 or higher, to complete a 10-minute survey about plus-size shopping. In order to reach a range of demographics, the researchers and graduate student volunteers posted the recruitment call on their social media. The advertisement also requested participants share and re-post the advertisement on their social media networks in order to increase the reach of participants. This method is also known as a snowball method that assists in recruiting individuals from a target group. A total of 422 respondents initiated the survey, $N=324$ were completed and included in data analysis. Participants were requested to complete a short demographic section and one questionnaire. Demographics included age, height, weight, country of residence, and waist measurement.

The questionnaire, titled Term Preferences, read: "Imagine that you are going on a shopping trip to find a blouse. Shopping stores and retailers have different terms and signs to describe the clothing section for larger women. Please indicate how desirable or undesirable you would find each of the following terms if you read it on a sign to indicate where larger clothing was located." The options were Women's, Large Size, Queen, Plus, Plus-Sizes, Plus Womenswear, Custom, Curvy, Outsized, Women's Plus, Womenswear, and Super Women's. Participants used a five-point 
scale (i.e., $1=$ very desirable, $2=$ desirable, $3=$ neutral, $4=$ undesirable, and $5=$ very undesirable) to rate each of the 12 terms. The researchers selected the terms through an academic literature review and with the assistance of plus-size consumers from the fashion program (who did not participate in the study). The terms were presented in the order listed above.

\section{Statistical analyses}

Participants were categorised based on body mass index (BMI) and age. BMI is a person's mass $(\mathrm{kg})$ divided by their height (m) squared. It is unofficially the US national system for body size measurement, as "The National Institutes of Health defines normal weight, overweight, and "obesity" according to BMI" (U.S. Department of Health and Human Services, 2013, p. 20). With the rise in larger bodies over the past century (Finucane et al., 2011), body size, or BMI classification, has become a critical concept in discourse and been used in fashion research (King, Shapiro, Hebl, Singletary, \& Turner, 2006). There are no official US sizing standards and sizing systems differ in measurements, labelling, and proportions (Dunn, 2016; Reczek \& Benson, 2016), making it difficult to classify human bodies by clothing sizes. Furthermore, the average woman has a range of five sizes in their wardrobe (Lubitz, 2016) and arranging participants according to garment size would have been problematic. Participants' BMI was calculated per the Center for Disease Control and Prevention "obesity" classifications: Overweight $=25-30$, "Obese" ${ }^{1} \quad \mathrm{I}=30-35$, "Obese" II $=35-40$, and "Obese" III $=40+$ (Centers for Disease Control and Prevention, 2016). Participants were also grouped by age; 18-35, 36-50, 51-64 and 65-78.

First, a multivariate analysis of variance was performed using SPSS. Within

1 The term "obesity" medicalizes human diversity and do harm to fat people. As fashion and fat studies scholars, "overweight", "obesity", "obese I, II,II" are placed in scare quotes in order to be consistent with the discourse we aim to represent.
Table 1: Demographic characteristics of participants $(n=234)$

\begin{tabular}{|c|c|c|c|}
\hline Factor & Range & $M$ & $S D$ \\
\hline Age & $18-76$ & 44.10 & 13.85 \\
\hline \multicolumn{4}{|l|}{ Weight } \\
\hline Pounds & $130-560$ & 226.42 & 54.33 \\
\hline Kilograms & $59-253$ & 102.7 & 24.64 \\
\hline \multicolumn{4}{|l|}{ Height } \\
\hline Inches & 48-83 & & \\
\hline Centimeters & $121.92-156.82$ & & \\
\hline \multicolumn{4}{|l|}{ Waist } \\
\hline Inches & $29-70$ & 41.56 & 7.2 \\
\hline Centimeters & 74-178 & 105.0 & 18.3 \\
\hline \multirow[t]{2}{*}{$\mathrm{BMI} \mathrm{kg} / \mathrm{m}^{2}$} & $17.8-97.6$ & 36.7 & 9.5 \\
\hline & & $\%$ & \\
\hline \multicolumn{4}{|l|}{ Race } \\
\hline \multicolumn{2}{|c|}{$\begin{array}{l}\text { American Indian } \\
\text { or Alaska Native }\end{array}$} & 2.0 & \\
\hline \multicolumn{2}{|c|}{ Asian } & 1.2 & \\
\hline \multicolumn{2}{|c|}{$\begin{array}{l}\text { Black or African America } \\
\text { Native }\end{array}$} & 2.0 & \\
\hline \multicolumn{2}{|c|}{ Hawaiian or Pacific Islander } & 1.0 & \\
\hline \multicolumn{2}{|c|}{ White or Caucasian } & 94.0 & \\
\hline \multicolumn{4}{|c|}{ Country of Residence } \\
\hline \multicolumn{2}{|c|}{ USA } & 94 & \\
\hline \multicolumn{2}{|c|}{ Canada } & $>2$ & \\
\hline \multicolumn{2}{|c|}{ Other: Australia, Asia } & $>1$ & \\
\hline
\end{tabular}

the BMI and age groups, the mean rating for each term was compared with that for the other eleven terms using Tukey's range test (Ramseyer \& Tcheng, 1973). To control for the number of tests directed, the experiment-wise error rate for each group of comparisons was set at $\alpha=.05$. Descriptive statistics were calculated for all participants. Differences in the ratings of BMI and age groups were further assessed by individual analysis of variance. Difference between groups, for ratings of individual terms, were considered statistically significant at $p \leq .05$.

\section{Results}

A total of 324 completed surveys were used in data analysis. Demographic data is presented in Table 1. Participants had a mean age of $44.1( \pm 13.85)$ years, mean weight of 226.4 ( \pm 54.33$)$ lbs., and a mean BMI of 36.7 $( \pm .58) \mathrm{kg} / \mathrm{m}^{2}$, classifying the mean BMI as 
Table 2: Demographic characteristics of participants in four BMI groups

\begin{tabular}{|c|c|c|c|c|c|c|c|}
\hline \multirow[t]{2}{*}{ Group } & \multirow[t]{2}{*}{$n$} & \multirow[t]{2}{*}{$M$} & \multicolumn{2}{|c|}{ Weight } & \multicolumn{2}{|c|}{ Height } & \multirow{2}{*}{$\begin{array}{c}\text { BMI } \\
\left(\mathrm{kg} / \mathrm{m}^{2}\right)\end{array}$} \\
\hline & & & Pounds & Kilograms & Inches & Centimeters & \\
\hline Overweight & 58 & $44 \pm 15.95$ & $177.05 \pm 16.64$ & $80.31 \pm 7.55$ & $66.73 \pm 2.96$ & $169.5 \pm 7.5$ & $27.92 \pm 1.33$ \\
\hline Obese I & 84 & $44.13 \pm 13.78$ & $200.89 \pm 20.78$ & $91.12 \pm 9.5$ & $66.08 \pm 3.31$ & $167.8 \pm 8.4$ & $32.28 \pm 1.47$ \\
\hline Obese II & 68 & $44.25 \pm 14.16$ & $234 \pm 22.8$ & $106.14 \pm 10.34$ & $66.12 \pm 2.86$ & $168 \pm 7.3$ & $37.55 \pm 1.45$ \\
\hline Obese III & 91 & $42.69 \pm 3.29$ & $258.23 \pm 54.13$ & $117.13 \pm 24.55$ & $64.73 \pm 3.29$ & $164.41 \pm 8.35$ & $47.92 \pm 9.23$ \\
\hline
\end{tabular}

Table 3: Demographic characteristics of participants in four BMI groups

\begin{tabular}{|c|c|c|c|c|c|c|c|}
\hline \multirow[t]{2}{*}{ Age Group } & \multirow[t]{2}{*}{$n$} & \multirow[t]{2}{*}{$M$} & \multicolumn{2}{|c|}{ Weight } & \multicolumn{2}{|c|}{ Height } & \multirow{2}{*}{$\begin{array}{c}\mathrm{BMI} \\
\left(\mathrm{kg} / \mathrm{m}^{2}\right)\end{array}$} \\
\hline & & & Pounds & Kilograms & Inches & Centimeters & \\
\hline 18-35 & 96 & $27.25 \pm 4.48$ & $223.5 \pm 48.05$ & $101.38 \pm 21.8$ & $65.96 \pm 3.54$ & $167.54 \pm 91$ & $36.32 \pm 8.48$ \\
\hline $36-50$ & 95 & $42.29 \pm 4.02$ & $240.44 \pm .51$ & $109.1 \pm 29.26$ & $66.35 \pm 3.49$ & $168.53 \pm 8.86$ & $38.73 \pm 10.9$ \\
\hline $51-64$ & 98 & $56.7 \pm 3.24$ & $220.67 \pm 50.38$ & $100.1 \pm 22.85$ & $65.90 \pm 2.67$ & $167.39 \pm 6.78$ & $35.82 \pm 9.44$ \\
\hline $65-78$ & 35 & $68 \pm 3.42$ & $208.75 \pm 45.71$ & $94.68 \pm 20.73$ & $65.56 \pm 4.86$ & $166.52 \pm 11.88$ & $34.35 \pm 8.36$ \\
\hline
\end{tabular}

Table 4: $\quad$ Ranking of preferred terms for plus size women

\begin{tabular}{llll}
\hline Rank & Term & $M$ & SD \\
\hline 1 & Women's & 1.97 & 0.93 \\
2 & Curvy & 2.64 & 1.23 \\
3 & Women's Wear & 2.65 & 1.15 \\
4 & Plus & 3.17 & 1.05 \\
5 & Women's Plus & 3.22 & 1.15 \\
6 & Custom & 3.26 & 1.17 \\
7 & Plus-Size & 3.33 & 1.05 \\
8 & Plus-Women's & 3.56 & 1.01 \\
9 & Large Size & 3.88 & 0.96 \\
10 & Oueen & 3.88 & 1.03 \\
11 & Super Women's & 4.41 & 0.78 \\
\hline 12 & Outsized & 4.69 & 0.59 \\
\hline
\end{tabular}

Preferred term was assessed using a five-point scale with anchors of Very Undesirable (5) to Very Desirable (1), SD=standard deviation

"obese" I. The largest group $(n=91)$, were classified within BMI of 35-40. Six per cent of the sample identified as minorities (including 2\% American Indian/Alaskan Native, 2\% Black/ African American, 1.2\% Asian, 1\% Pacific Islander/Hawaiian) and 94\% identified as Caucasian. The majority of respondents were from the United States with small responses from Canada, Australia, and Asia.

Participants' BMI was calculated to determine "obesity" classifications (i.e., BMI >40). Table 2 characterises participants by BMI into ranges set by the Center for Disease Control and Prevention. The largest group $(\mathrm{n}=91)$ were within a BMI of 35-40.

Participants were also grouped by age. Table 3 demonstrates demographics divided by age into 18-35, 36-50, 51-64 and $65-78$. The smallest age group $(n=35)$ represented ages 65-78.

\section{RQ1. What are the most and least}

preferred terms for plus-size women? Table 4 demonstrates ranking and mean ratings of each term in all age and BMI groups. Of the twelve terms, the most preferred terms were: Women's, Curvy, and Womenswear. The nine remaining terms were rated as neutral, undesirable and very undesirable. The terms Outsized, Super Women's, Queen, Large Size, Plus Womenswear, Plus-Size, Custom, Plus, and Women's Plus were rated more undesirable than neutral or desirable.

\section{RQ2. Whether or not BMI has an effect on plus-size women's preferred terms for apparel signage.}

While there are significant differences between women by BMI, the mean scores indicate that all women, excluding body mass, have similar preferences in store signage. There is a significant difference in the mean scores of terms based on BMI (Roy's largest root $=0.001$, F $(12,242)=2.849, \mathrm{p}<0.05)$. The findings reveal that four terms had significant dif- 
Table 5: Demographic characteristics of participants $(n=234)$

\begin{tabular}{lllll}
\hline Group & Large Size & Queen & Super Women's & Outsized \\
\hline Mean \pm SD & & & & \\
"Overweight" & $3.61 \pm 1^{*}$ & $3.76 \pm .993$ & $4.17 \pm .825^{*}$ & $4.80 \pm .401^{*}$ \\
"Obese" | & $3.88 \pm .993$ & $3.91 \pm 1.08$ & $4.42 \pm .753$ & $4.70 \pm .542$ \\
"Obese" || & $3.89 \pm 8.96$ & $4.09 \pm 1.04^{*}$ & $4.58 \pm .599^{*}$ & $4.53 \pm .813^{*}$ \\
"Obese" ||I & $3.99 \pm 9.47^{*}$ & $3.71 \pm 1.03^{*}$ & $4.41 \pm .797$ & $4.69 \pm .610$ \\
\hline Sign & .035 & .037 & .007 & .024 \\
\hline
\end{tabular}

Preferred term was assessed using a five-point scale with anchors of Very Undesirable (5) to Very Desirable (1)

*indicates significance $p<.05$

ferences in preference depending on BMI group. Women classified as "Obese" I are significantly more likely to prefer the term Large Size $(p=.035)$ than "overweight" women. Women classified as "Obese" II are significantly more likely to prefer the term Queen ( $p=.037)$ than "Obese" III women. The term Super Women's is slightly more likely $(p=.007)$ to be preferred amongst women in the "Obese" II group than "overweight" women. The term Outsized was more likely to be preferred by Overweight women $(p=.024)$ than "Obese" II women. Findings reveal non-significant differences in the remaining terms. The term Women's was the highest rated option, deemed as very desirable and desirable by $72 \%$ of Overweight women, $78 \%$ of "Obese" I women, $74 \%$ of "Obese" II women, and $72 \%$ "Obese" III women. Table 5 demonstrates the significant differences found in term preferences between BMI groups.

\section{RQ3. Whether age effects plus-size women's preferred terms for apparel signage.}

The highest rated term by all age groups was Women's. Seventy-seven per cent of women aged 18-35 rated Women's as very desirable and desirable with similar ratings of $69 \%$ amongst $36-50$ aged women, $77 \%$ amongst 51-64 year-old women and $73 \%$ by women age $65-78$. There was a significant difference between age groups when considered jointly on their term preferences for apparel signage, Wilks $\Delta=.810, \quad \mathrm{~F}(36,768.927)=1.579, p<.018$, partial $\eta^{2}=.068$. A separate analysis of variance was conducted for each dependent variable and evaluated at $\alpha=0.05$. Significant differences between age groups on five terms including Queen, Women's, Large Size, Super Women's, Curvy, and Womenswear. The term preference Queen, $\mathrm{F}(3,271)=1.516, p=.014$, partial $\eta^{2}=.038$, is statistically more preferred amongst 51-64 year olds $(M=4.09)$ than every other age group; 18-35 year olds $(\mathrm{M}=3.60), 36-50$ year olds $(\mathrm{M}=3.96)$, and $65-78$ year olds $(M=3.84)$. There was a significant difference between age groups on the term preference Curvy, $\mathrm{F}(3,271)=3.131, p=.026$, partial $\eta^{2}=.034$, with $65-78$ year olds $(\mathrm{M}=3.00)$ statistically less likely to prefer the term than 18-35 ( $M=2.55), 36-50$ year olds $(\mathrm{M}=2.42)$, and $51-64$ year olds $(\mathrm{M}=2.91)$. Women's was slightly less preferred by $65-78$ years old $(\mathrm{M}=2.28)$ than $51-54$ year olds $(\mathrm{M}=1.81)$. The term Super Women's was significantly less preferred by $36-50(\mathrm{M}=4.47)$ and $51-64(\mathrm{M}=4.47)$ than older women aged 65-78 $(\mathrm{M}=4.12)$. The last term, Womenswear, was more desired by ages $36-50(\mathrm{M}=.79)$ than women aged 65-78 $(\mathrm{M}=2.92)$. There was not a significant difference between age groups on terms Large Size, Super Women's, Plus, Plus Size, Plus-Womenswear, Women's Plus, Custom, Outsized, or Womenswear.

Excluding age and BMI, $96 \%$ of the sample rated Women's, as neutral and very desirable. Indicating that $96 \%$ of plus-size women prefer the term Women's over Plus-Size as a clothing size designation. Seventy-eight per cent rated Womenswear as neutral, desirable or very desirable, and $73.44 \%$ reported Curvy as neutral, desirable, and very desirable. On the other hand, 99\% reported Outsized, 97.04\% reported Super Women's, and 91.78\% reported Large Size as very undesirable, undesirable, or neutral. The ma- 
jority of all age groups and BMI reported the term Queen to be undesirable or very undesirable. While there are significant differences between age and BMI for the undesirable terms, based on the mean scores, Outsized, Super Women's, Large Size and Queen are not recommended for designating women's plus-size clothing in the fashion industry. The terms, in order of desirability, for plus-size consumers is Women's, Womenswear and Curvy.

\section{Open-ended comments}

At the end of the survey, an open-ended prompt elicited comments or suggestions about language used in the apparel industry. Thirty-eight per cent, or 124 participants commented in response to the query, "Please provide comments or suggestions for other terms to describe apparel for larger women." Five themes emerged from both long and short comments: 1. Questioning current practices, 2. Suggesting new practices, 3 . Confirming a merchandising term, 4. Suggesting a new name, and 5. Discrimination, segregation, and separation.

Three coders independently analysed the comments and conducted a binary analysis to calculate Krippendorff's alpha inter-coder reliability estimates for each theme (Hayes \& Krippendorff, 2007). Reliability coefficients for each category were as follows: 1. Questioning the current practices $(\alpha=0.93), 2$. Suggesting new practices $(\alpha=0.70), 3$. Confirming a merchandising term $(\alpha=0.91), 4$. Suggesting a new name $(\alpha=0.77)$, and 5. Discrimination, Segregation, and Separation $(\alpha=0.73)$. Each comment was treated as the unit of analysis, with the five themes being coded for presence/non-presence for each response. New merchandising names and new practices for organising or labelling clothing were recorded to look for similarities within those themes.

\section{Questioning the current practices}

One-quarter of the comments included a question about how or why plus-size clothing is labelled or categorised as plus- size. The sentiments reflected confusion, frustration, and annoyance with the current clothing system. For example:

, One participant commented, Why can't all Women's clothes be called just "Women's"?

, Another participant commented, Why do they even need distinguishers for women that are larger? Why does a 22 all of a sudden become a big X? or a PLUS? Why doesn't clothing simply have numbers to measure the size? I don't understand the need to separate plus size and "normal" size clothing in a store anyways. Women are women regardless of size.

, Another participant further commented, Why does there have to be another term. Why can't stores just have racks with different sizes. We're bigger, not stupider, we can read sizes.

\section{Suggesting new practices}

Nearly one-third of the comments included a suggestion for a new practice of clothing categorisation or placement. Of these, the two most frequent suggestions included 1) using physical body measurements, as with men's clothing, and 2) organize all women's clothing in the same section. For example;

, One participant commented, All sizes are on the same rack, all styles should be in the same section, regardless of size.

, Another participant commented, It may not be appealing, but ALL clothing needs to be by measurement. No guessing involved. There needs to be a standard across the industry.

, Why not use actual measurements, like they do for men's clothing?

\section{Confirming a merchandising term}

Nearly one fourth of the comments were a confirmation or reinforcement of the terms used in the survey. The comments appeared to justify or add reasoning to their term selection while also crossing between other themes such as questioning the current practices. For example;

, One participant commented, How about Women's -no qualifier needed. 
> Another participant commented, I'm ok with plus size, no need to cause confusion than [sic] it already can be.

, Another participant further commented, I really like the use of women's wear. I don't understand why clothing isn't just labeled [sic] according to size though. Why do they even need distinguishers for women that are larger?

\section{Suggesting a new name}

Forty per cent of the comments suggested new terms that were not included in the survey. Of these, the most common term recommendations were "full figured", "extended sizes", and "real women". Several comments included the desire for new words without, for example, "loaded values."

\section{Discrimination, segregation, and separation.}

Approximately one-fourth of the responses specifically addressed feelings of being separated or treated as other. These comments were similar to many of those suggesting a new practice. For example;

, One participant commented, How about just put all the clothes together so we can all shop for the same thing without feeling shamed into finding the large size section stashed behind the shoes where no one can see us.

> Another participant commented, I don't think there should be different sections. There should just be clothes, and the 'regular' clothing should come in all the sizes. Stop marginalising [sic] us.

, Another participant commented, The clothing should not be separate in the women's section. Meaning, it should not be segregated to another section.

\section{Discussion}

Plus-size women in this study rated the majority of merchandising terms very undesirable/ undesirable for communication in the fashion industry. Respondents felt that many terms are divisive because of the segregation used in merchandising. The majority preferred the term Women's to describe their apparel and many objected to the method of segregating plus-sized clothing. People with larger bodies in the United States accept discrimination with regularity and the findings of this study suggest that women who wear plus-size want to be viewed as women and not as a different group or other.

The examination of language for women who wear plus-size provides critical insight as to how fashion communication further marginalises women and perpetuates elitism in the fashion industry by grouping women in sizing categories. Cultural discourses stigmatise plus-size as unattractive and unhealthy. Perhaps the use of the term plus-size is a method to maintain the status quo of the in-group. The fashion industry has mirrored this discourse and created a clear divide between the attractive/healthy/in-group and the unattractive/unhealthy/out-group. The groups' language and communications vary between clothing brands and maintain the plus-size consumer in a constant state of confusion and in doing so, keeps the power in fashion reserved for the thin. As one respondent asked: "Imagine if plus was the normal section, and everything else were minus or straight size. Wouldn't it feel weird? But we do it to us fat people all the time." This comment highlights one example of how communication in the fashion industry is rooted in thin privilege (Bacon et al., 2016).

Many companies have marketed products for women who wear plus-size with the purpose of embracing diversity, exposing and criticising thin-privilege, elitism, and exclusion which are still at the heart of the fashion industry. While many Americans claim to value equality, the inequality and discrimination in groupings that frame women by clothing size is evident. Whether implicit or explicitly bias, retailers that limit sizes are in itself direct evidence of those companies' view of larger women.

Some participants commented the word plus-size is acceptable and politically correct. For example, one participant stated: "I'm ok with plus size, no need to cause confusion than [sic] it already can 
be". While other participants and feminist scholars feel euphemisms such as heavy, large, voluptuous, and big-boned are only used by people who find the truth distasteful (Wann, 1998). Wann (2009) suggested that plus-size women should embrace the word "fat" and reclaim it as any other adjective such as tall or short. The difference in views can be understood through social identity theory. As humans are motivated to avoid uncertainty and ambiguity (Kruglanski, 2004; Kruglanski, Pierro, Mannetti, \& De Grada, 2006) some women prefer to maintain the plus-size clothing group because dismantling it would cause confusion.

Further illustrating social identity with clothing size, participants reported experiencing unfair treatment when shopping. It has been found that even the smallest hint of categorisation, leads people to favour their own groups (Tajfel, Billig, Bundy \& Flament, 1971). Group experiments have found that the mere fact of a grouping of people produces ethnocentrism and competitive intergroup behaviour (Diehl, 1990). Through social identity theory, plus-size women are the out-group to the smaller sized/normal/ regular women's in-group, which may be viewed as a major threat to the virtuous nature of the thin in-group. Thin individuals are viewed as having, and thus valuing, willpower, adherence to diets and a superior morale (Bacon et al., 2016). Defending and preserving in-group values against out-groups may be construed as a moral imperative and perhaps drive implicit and bias behaviours (Mummendey \& Otten, 1998). Maintaining the distinction between groups functions to protect the thin in-group because group threats are interpreted as individual threats (Thomas, McGarty \& Mavor, 2016). For example, stating that plus-size clothing takes up too much valuable floor space (Pinckney, 2014) is an attempt to justify the practice, maintain the groups, and ward off accusations of prejudice and discrimination.

Our findings show that women who are out-group (plus-size), despite age or BMI, simply want to be referred to, and classified with the in-group (women).
Social identity theory posits that when there is competition for a positive identity, individuals who already possess the positive identify are motivated to enhance and protect their identities (Rubin \& Hewstone, 2004). As we've found, there are many negative associations and experiences as a plus-size consumer, and therefore dismantling the segregated sizing classification is a key motivation for plus-size women. However, the belief of social mobility, leaves some women striving to permeate the group boundaries. Meaning, some plus-size women need the group boundaries to define their success if they are able to join the in-group. Evidence of this attempt to change body size and wear smaller clothing, can be seen in the 60-billion-dollar revenue of the diet and weight loss industry (Williams, 2013). In another example, Gruys (2012) found that plus-size women who talked about wanting to lose weight received better customer service than women who did not. This indicates that the boundaries of clothing size groups are culturally agreed upon as an easy threshold to cross and explain why women who express a desire to lose weight are treated with more respect during clothes shopping.

The concept of clothing size in-group and out-group is a social construction of the good and bad body. Group status is communicated on clothing size labels and the interpretation of those sizes is culturally bound. Perhaps a shift in language and fashion communication can contribute to identity beyond the physical. In thinking of consumers primarily as women, and secondarily as clothing wearers, we can shift the thought process from $I$ am a size to I wear a size

Aspects of clothing, retail, and consumer experiences affect plus-size women's social identity, and in this examination, we expose the hierarchy of in-groups and outgroups in the fashion industry. Redefining the social value and restructuring the practices within fashion communications related to sizing, merchandising, designing, advertising, marketing, and retailing for plus-size women is needed. However, restructuring of fashion communication 
is unlikely unless the in-group recognises their thin-privilege and makes concerted efforts towards equality and inclusion instead of aggressively attempting to maintain the current segregated sizing system (Jetten, McAuliffe, Hornsey \& Hogg, 2006).

This study of language and fashion communication goes beyond surface level and reveals the deeper construction of power through social identity in the fashion industry. Plus-size women account for 67 per cent of the US population (Bauknecht, 2014) and addressing social identity could positively impact women's self-image. This study looked at the word plus-size as communicated as a merchandising classification and reinforced the anecdotal evidence found in popular American fashion literature. Generalizing the data beyond North America would not be appropriate at this time and further studies are needed. With a smaller sample size, there is also random variability to consider. With the current sample of $\mathrm{N}=324$, we can expect $5-7 \%$ variability in estimates for generalizing the findings (Fay, Halloran \& Follmann, 2007) and the researchers believe the results to be generalizable to North America. While the scope of this paper does not include the logistics of implementing the practice of merchandising all Women's sizes together, it is evident that the overwhelming majority of women who wear plus-size desire to eradicate clothing size segregation. As suggested by many comments and confirmed through anecdotal popular press (Avilia, 2015; Wang, 2015), a switch to measurements as the size designation, similar to Men's clothing, may be a possible solution. Areas of future research include surveying other marginalised demographics and retailers that group consumers by size, such as 'big and tall' stores. Further study of clothing size communication and social identity would be of benefit to understand social belief structures for new and emerging markets.

\section{References}

Alexander, M., Pisut, G.R. \& Ivanescu, A., (2012). Investigating women's plus-size body measurements and hip shape variation based on Size. USA data. International Journal of Fashion Design, Technology and Education, 5(1), 3-12. doi:10.1080/ 17543266.2011.589083

Allik, J. \& Realo, A., (2004). Individualism-collectivism and social capital. Journal of Cross-Cultural Psychology, 35(1), 29-49. doi:10.1177/0022022103260381

Anderson, E.T. \& Simester, D.I., (2008). Research note-does demand fall when customers perceive that prices are unfair? The case of premium pricing for large sizes. Marketing Science, 27(3), 492-500.

Asbury, M.E., (2011). Exploring Weight Identity: An Examination of the Cognitive, Affective, and Behavioral Components of Weight, (Doctoral Dissertation, University of Kansas).

Avilia, T. (2015, October 27). We asked women what they think of the term "plus-size" here's what they had to say. Mic Network Inc. Retrieved from https://mic.com/articles/127415/we-asked-women-what-theythink-of-the-term-plus-size-here-s-whatthey-had-to-say\#.oSn7HNcCD

Bacon, L., O’Reilly, C., \& Aphramor, L. (2016). Reflections on Thin Privilege and Responsibility. In E. Cameron and C. Russell (Eds.), The fat pedagogy reader: Challenging weight-based oppression in education (pp. 41-50), New York, NY: Peter Lang Publishing.

Bauknecht, S. (2014, July 20). Fashion Brands Branching Out with More Plus-Size Options. Pittsburg Post-Gazette. Retrieved from http://www.post-gazette.com/life/ fashion/2014/07/21/Style-for-all-sizesFashion-brands-expand-plus-size-options-with-extended-sizes-new-collections/stories/201407210004

Bogart, K. R. (2015). Disability identity predicts lower anxiety and depression in multiple sclerosis. Rehabilitation Psychology, 60(1), 105-109. doi:10.1037/rep0000029

Bogenrief, M. (2012, December 21). Retailers can't ignore 100 million plus-size women forever. Business Insider. Retrieved from http://www.businessinsider.com/whyisnt-plus-size-bigger-2012-12

Brown, P. \& Rice, J. (2014). Sizing (Eds.) Readyto-wear apparel analysis, (pp. 207). Upper Saddle River, NJ: Prentice Hall. 
Buse, C.E. \& Twigg, J. (2015). Clothing, embodied identity and dementia: Maintaining the self through dress. Age, Culture, Humanities, 2, 1-32.

Celik, H. (2016). Customer online shopping anxiety within the unified theory of acceptance and use technology (UTAUT) framework. Asia Pacific Journal of Marketing and Logistics, 28(2), 278-307.

Christel, D. A. (2016). The efficacy of problem-based learning of plus-size design in the fashion curriculum. International Journal of Fashion Design, Technology and Education, 9(1), 1-8. doi: 10.1080/17543266.2015.1094518

Christel, D. A. (2014). It's your fault you're fat: Judgements of responsibility and social conduct in the fashion industry. Clothing Cultures, 1(3), 303-320.

Christel, D. A. \& Dunn, S. C. (2016). Average American women's clothing size: Comparing National Health and Nutritional Examination Surveys (1988-2010) to ASTM International Misses \& Women's Plus Size clothing. International Journal of Fashion Design, Technology and Education, 10(2), 1-8. doi: 10.1080/17543266.2016.1214291

Christel, D. A., O’Donnell, N. H., \& Bradley, L. A. (2016). Coping by crossdressing: An exploration of exercise clothing for "obese" heterosexual women. Fashion and Textiles, 3(1), 1-19. doi:10.1186/s40691016-0063-Z

Czerniawski, A. M. (2015). Fashioning Fat: Inside Plus-Size Modeling. New York, NY: NYU Press.

Diedrichs, P. C. \& Puhl, R. (2016). Weight bias: Prejudice and discrimination toward overweight and "obese" people. In Sibley, C. \& Barlow, F. K., (Eds), The Cambridge Handbook of the Psychology of Prejudice (pp. 392-412). Cambridge, UK: Cambridge University Press.

Diehl, M., (1990). The minimal group paradigm: Theoretical explanations and empirical findings. European review of social psychology, 1(1), 263-292. doi:10.1080/14792779108401864

Dove.com (2016). About Dove. Retrieved from http://www.dove.com/us/en/stories/ about-dove.html

Dunn, S. C. (2016). Women's plus-size apparel: Assessment of clothing size charts among
National Retail Federation's 2015 Top 100 US retailers (Masters Thesis). Retrieved from http://www.dissertations.wsu.edu/ Thesis/Spring2016/S_Dunn_060116.pdf

Durso, L. E., Latner, J.D. \& Ciao, A.C. (2016). Weight bias internalization in treatment-seeking overweight adults: Psychometric validation and associations with self-esteem, body image, and mood symptoms. Eating Behaviour, 21, 104-108.

Eisenberg, M. H., Street Jr, R.L, \& Persky, S. (2016). "It runs in my family ...": The association of perceived family history with body dissatisfaction and weight bias internalization among overweight women. Women \& Health, 1-16.

Fay, M., Halloran, M., \& Follmann, D. (2007). Accounting for Variability in sample size eestimation with applications to nonadherence and estimation of variance and effect size. Biometrics, 63(2), 465-474. Retrieved from http:// www.jstor.org/stable/4541358

Finucane, M. M., Stevens, G. A., Cowan, M. J., Danaei, G., Lin, J. K., Paciorek, C. J., \& Farzadfar, F. (2011). National, regional, and global trends in body-mass index since 1980: Systematic analysis of health examination surveys and epidemiological studies with 960 country-years and 9.1 million participants. The Lancet, 377(9765), 557-567.

Garcia, T. (2015, October 15). ModCloth says $60 \%$ of plus-size women are embarrassed to shop Separately. Market Watch, Retrieved from http://www.marketwatch. com/story/modcloth-says-60-of-plussize-women-areembarrassed-to-shopseparately-2015-10-08

Garstka, T.A., Hummert, M.L. \& Branscombe, N.R., (2005). Perceiving age discrimination in response to intergenerational inequity. Journal of Social Issues, 61(2), 321-342.

Gruys, K. (2012). Does this make me look fat? Aesthetic labor and fat talk as emotional labor in a women's plus-size clothing store. Social Problems, 59(4), 481-500. doi:10.1525/sp.2012.59.4.481

Hayes, A. F., \& Krippendorff, K. (2007). Answering the call for a standard reliability measure for coding data. Communication Methods and Measures, 1, 77-89. 
Jetten, J., McAuliffe, B.J., Hornsey, M.J. \& Hogg, M.A. (2006). Differentiation between and within groups: the influence of individualist and collectivist group norms. European Journal of Social Psychology, 36(6), 825-843. doi.org/10.1002/ejsp.322

Kim, H. Y., Jolly, L., \& Kim, Y. K. (2007). Future forces transforming apparel retailing in the United States: An environmental scanning approach. Clothing and Textiles Research Journal, 25(4), 307-322. doi:10.1177/0887302X07306851

King, E. B., Shapiro, J. R., Hebl, M. R., Singletary, S. L., \& Turner, S. (2006). The stigma of "obesity" in customer service: A mechanism for remediation and bottom-line consequences of interpersonal discrimination. Journal of Applied Psychology, 91(3), 579-593. doi:10.1037/0021-9010.91.3.579

Kruglanski, A. W. (2004). The psychology of closed mindedness. New York: Psychology Press.

Kruglanski, A. W., Pierro, A., Mannetti, L., \& De Grada, E. (2006). Groups as epistemic providers: Need for closure and the unfolding of group-centrism. Psychological Review, $113,84-100$.

Lee, J. \& Steen, C. (2015), Size charts. In Lee. J \& Steen, C (Eds.). Technical sourcebook for designers (pp.277-280). New York, NY: Bloomsbury.

Lubitz, R. (2016, December 20). This woman proved once and for all that clothing sizes don't mean a thing. Business Insider, Retrieved from http://www.businessinsider. com/woman-proves-clothing-sizes-arebs-2016-12

McLeod, S. A. (2008). Social identity theory. Simple Psychology, Retrieved from https:// www.simplypsychology.org/social-identity-theory.html

McMichael, L., (2013). Acceptable prejudice?: Fat, rhetoric and social justice. Pearlsong Press.

Mummendey, A. \& Otten, S., (1998). Positivenegative asymmetry in social discrimination. European Review of Social Psychology, 9(1), 107-143.

Nagar, K. \& Gandotra, P. (2015). Exploring choice overload, internet shopping anxiety, variety seeking and online shopping adoption relationship: Evidence from on- line fashion stores. Global Business Review, 17(4), 851-869.

Norman, D. (2017, July 7). What's up with these inconsistent plus-size clothing sizes? The Curvy Fashionista, Retrieved from http:// thecurvyfashionista.com/2017/07/plussize-clothing-sizes/

Pauletti, R.E., Cooper, P.J., Aults, C.D., Hodges, E.V. \& Perry, D.G., (2016). Sex differences in preadolescents' attachment strategies: Products of harsh environments or of gender identity? Social Development, 25(2), 390-404.

Peters, L. D. (2015). You are what you wear: How plus-size fashion figures in fat identity formation. Fashion Theory: The Journal of Dress, Body Culture, 18(1), 45-72. doi:10. 2752/175174114X13788163471668

Pinckney, T., (2014). Shopping in a size small world: Examining attributes of mainstream retail clothing stores that affect the level of satisfaction in plus-size female consumers (Unpublished Master's Thesis). University of South Carolina.

Plusisequal.com (2016). It's time to represent. Retrieved from www.plusisequal.com/ Refinery29. (2016, January 29). A look at how plus-size women have been marginalized by fashion throughout history. Yahoo Lifestyle. Retrieved from https://www.yahoo. com/beauty/a-look-at-how-plus-sizewomen-have-been-204506716.html

Ramseyer, G. C. \& Tcheng, T. K. (1973). The robustness of the studentized range statistic to violations of the normality and homogeneity of variance assumptions. American Educational Research Journal, 10(3), 235-240.

Reczek, K., \& Benson, L. M. (2016). A Guide to United States Apparel and Household Textiles Compliance Requirements (No. NIST Interagency/Internal Report (NISTIR)-8115). Retreived from https:// www.nist.gov/publications/guide-united-states-apparel-and-household-textiles-compliance-requirements

Rothblum, E.D. \& Solovay, S. (2009). The fat studies reader. (Eds.) NYU Press.

Rubin, M. \& Hewstone, M. (2004). Social identity, system justification, and social dominance: Commentary on Reicher, Jost et al., and Sidanius et al. Political Psychology, 25(6), 823-844. 
Ryan, M.S. (1966). Clothing: a study in human behavior. New York,: Holt, Rinehart and Winston.

Scaraboto, D., \& Fischer, E. (2016). Frustrated fatshionistas: An institutional theory perspective on consumer quests for greater choice in mainstream markets. Journal of Consumer Research, 39(6), 1234-1257.

Tajfel, H. \& Turner, J. C. (1979). An integrative theory of intergroup conflict. In W. G. Austin \& S. Worchel (Eds.), The social psychology of intergroup relations (pp. 33-47), Monterey, CA: Brooks/Cole.

Tajfel, H., Billig, M.G., Bundy, R.P. \& Flament, C., 1971. Social categorization and intergroup behaviour. European Journal of Social Psychology, 1(2), 149-178.

Tajfel, H. \& Turner, J. C. (1986). The social identity theory of intergroup behaviour. In S. Worchel \&W. G. Austin (Eds.), Psychology of intergroup relations, (pp. 7-24), Chicago, IL: Nelson.

Thomas, E. F., McGarty, G. \& Mavor, K. (2016). Group interaction as the crucible of social identity formation: A glimpse at the foundations of social identities for collective action. Group Processes \& Intergroup Relations, 19(2), 137-151.

Tiggemann, M., \& Lacey, C. (2009). Shopping for clothes: Body satisfaction, appearance investment, and functions of clothing among female shoppers. Body Image, 6(4), 285-291.

Twigg, J. (2014), Clothing, identity and the embodiment of age. Textile-led Design for the Active Ageing Population (pp. 13) University of Kent; Canterbury.

US Department of Health and Human Services, Centers for Disease Control and Prevention. (2013). The State of Aging and Health in America 2013. (Vol. 6). Retrieved from https://www.cdc.gov/aging/pdf/stateaging-health-in-america-2013.pdf

Wang, C. (2015). Melissa McCarthy is not a fan of the term "plus-size" for some very legit reasons. Refinery29. Retrieved from http:// www.refinery29.com/2015/08/92450/melissa-mccarthy-plus-size

Wann, M. (1998). Fat! So?: Because you don't have to apologize for your size! New York, NY: Ten Speed press, a division of Random House, Inc.
Wann, M. (2009). Forward: Fat studies: An invitation to revolution. In E. Rothblum \& S. Solvay (Eds), The fat studies reader (pp. ixxxv), New York: New York Press.

Williams, G. (2013, January 2). The heavy price of losing weight. US News. Retrieved from https://money.usnews.com/money/personal-finance/articles/2013/01/02/theheavy-price-of-losing-weight.

\section{Acknowledgements}

The authors would like to express their gratitude to the women who participated in the survey and those who assisted with recruitment. We would also like to acknowledge Yini Chen and Becky James for assistance in coding and editing the manuscript. This work was not funded by any granting agencies. This study satisfies the criteria for exempt research at 45 CFR 46.101(b)(2) by a state university Institutional Review Board under study (IRB \# 15277).

\section{Authors note}

The term "obesity" medicalizes human diversity and do harm to fat people. As fashion and fat studies scholars, ,overweight”, "obesity", "obese I, II, II" are placed in scare quotes in order to be consistent with the discourse we aim to represent. 